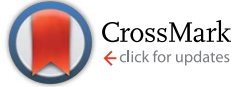

Cite this: J. Mater. Chem. A, 2014, 2 , 18917

Received 4th July 2014

Accepted 8th September 2014

DOI: $10.1039 / c 4 t a 03421 j$

www.rsc.org/MaterialsA

\section{A solution-processed barium hydroxide modified aluminum doped zinc oxide layer for highly efficient inverted organic solar cells $\uparrow$}

\author{
Hong Zhang, ${ }^{\text {acc }}$ Tobias Stubhan, ${ }^{a}$ Ning Li, ${ }^{a}$ Mathieu Turbiez, ${ }^{d}$ Gebhard J. Matt, ${ }^{a}$ \\ Tayebeh Ameri ${ }^{a}$ and Christoph J. Brabec ${ }^{a b}$
}

\begin{abstract}
Inverted organic solar cells (iOSCs) with air stable interface materials and top electrodes and an efficiency of $6.01 \%$ are achieved by inserting a barium hydroxide $\left(\mathrm{Ba}(\mathrm{OH})_{2}\right)$ layer between the aluminum doped zinc oxide (AZO) electron extraction layer and the active layer. A low bandgap diketopyrrolopyrrolequinquethiophene alternating copolymer (pDPP5T-2) and phenyl-C61-butyric acid methyl ester $\left(\mathrm{PC}_{61} \mathrm{BM}\right)$ were chosen as the active layer compounds. Compared to the control device without $\mathrm{Ba}(\mathrm{OH})_{2}$, insertion of a few $\mathrm{nm}$ thick $\mathrm{Ba}(\mathrm{OH})_{2}$ layer results in an enhanced $\mathrm{V}_{\mathrm{OC}}$ of $10 \%, \mathrm{~J}_{\mathrm{SC}}$ of $28 \%$, $\mathrm{FF}$ of $28 \%$ and PCE of $80 \%$. Modification of AZO with a solution processed low-cost $\mathrm{Ba}(\mathrm{OH})_{2}$ layer increased the efficiency of the inverted device by dominantly reducing the energy barrier for electron extraction from $\mathrm{PC}_{61} \mathrm{BM}$, and consequently, reduced charge recombination is observed. The drastic improvement in device efficiency and the simplicity of fabrication by solution processing suggest $\mathrm{Ba}(\mathrm{OH})_{2}$ as a promising and practical route to reduce interface induced recombination losses at the cathode of organic solar cells.
\end{abstract}

\section{Introduction}

Organic solar cells (OSCs) were studied intensively in the last decade due to their remarkable properties such as mechanical flexibility, low-cost, light weight and low energy consuming rollto-roll manufacturing process. ${ }^{1-4}$ Recently, OSCs showed impressive power conversion efficiency (PCE) with over $10 \%$ for a laboratory test cell. ${ }^{5}$ Developing the OSC technology towards industrial commercialization is thus the focus of extensive research. The physical and chemical properties of the semiconductor/electrode interface were found to be the most critical factors in determining the device characteristics and stability. ${ }^{6}$

Inverted organic solar cells (iOSCs) rapidly evolved with the progress of n-type inorganic metal oxides $\left(\mathrm{MeO}_{\mathrm{x}}\right)$ as electron transport layers, such as titanium oxide $\left(\mathrm{TiO}_{\mathrm{x}}\right)$, zinc oxide $(\mathrm{ZnO})$ or aluminum doped zinc oxide (AZO). ${ }^{7-12}$ Metal oxides have emerged because of their intrinsically higher environmental stability as compared to poly(3,4-ethylenedioxythiophene):

${ }^{a}$ Institute of Materials for Electronics and Energy Technology (i-MEET), Friedrich-Alexander-University Erlangen-Nuremberg, Martensstraße 7, 91058 Erlangen, Germany. E-mail: Hong.Zhang@fau.de; Fax: +49 (o)9131-8528495; Tel: $+49(0) 9131-8527722$

${ }^{b}$ Bavarian Center for Applied Energy Research (ZAE Bayern), Haberstraße 2a, 91058, Erlangen, Germany

'Erlangen Graduate School in Advanced Optical Technologies (SAOT), Paul-GordanStraße 6, 91052 Erlangen, Germany

${ }^{d}$ BASF Schweiz AG, Schwarzwaldallee 215, CH-4002 Basel, Switzerland

$\dagger$ Electronic supplementary information (ESI) available. See DOI: $10.1039 / \mathrm{c} 4 \mathrm{ta} 03421 \mathrm{j}$ poly(styrenesulfonate) (PEDOT:PSS) or calcium (Ca) charge transport layers. ${ }^{13}$ However, solution processed metal oxides are far away from the properties of single crystals, and defect related energy levels or Schottky barriers may form interfacial barriers. ${ }^{14-18}$ Lee et al. and others reported poor electron injection and extraction in/from organic optoelectronic devices with metal oxide interfacial layers due to a contact barrier between the n-type metal oxides and the lowest unoccupied molecular orbital (LUMO) of the acceptor of the active layer. ${ }^{6,19-21}$ Schematics of various types of energy level mismatch between the ntype metal oxides $\left(\mathrm{MeO}_{\mathrm{x}}\right)$ and the acceptor of the active layer (PCBM) and their implication on the $j-V$ characteristics are shown in Fig. 1. 15,22,23 (a) An injection barrier is formed when the work function of the $\mathrm{MeO}_{\mathrm{x}}$ is below the Fermi level, the LUMO level of PCBM, respectively. Such an injection barrier prevents electron injection at the $\mathrm{MeO}_{\mathrm{x}} / \mathrm{PCBM}$ interface. An injection barrier primarily implies an increased series resistance, and, if contact formation follows the integer charge transfer (ICT) model, ${ }^{24}$ a potentially lower built-in potential $V_{\text {bi }}$ (as compared to the $\mathrm{HOMO}_{\text {donor }}-\mathrm{LUMO}_{\text {acceptor }}$ difference). A delayed injection results in a higher series resistance or even an s-shaped $j-V$ curve in the $1^{\text {st }}$ quadrant in combination with a potentially lower $V_{\text {OC }}$ (b) An extraction barrier implies that charges cannot be extracted from the active layer to the metal oxide because the conduction band of $\mathrm{MeO}_{\mathrm{x}}$ is high above the LUMO of PCBM. Such an extraction barrier becomes visible as a strong bias dependence of the photocurrent under reverse bias, i.e. in the $3^{\text {rd }} / 4^{\text {th }}$ quadrant. (c) The combination of extraction and injection barriers results in an s-shaped $j-V$ curve ( $1^{\text {st }}$ quadrant) in 


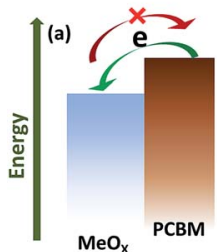

(b)

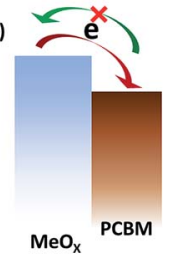

Injection barrier

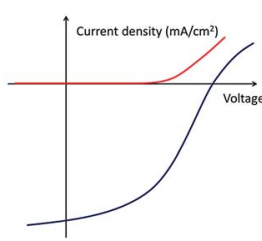

Extraction barrier
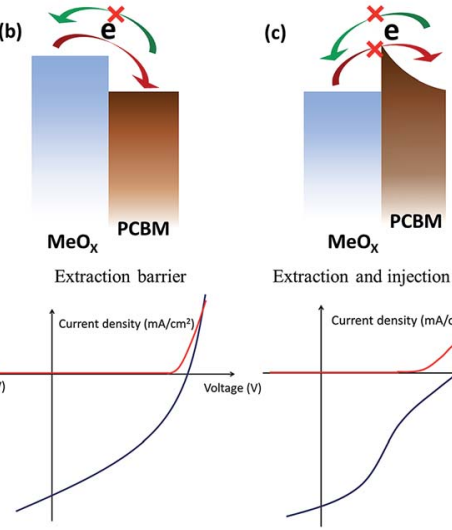

Extraction and injection barrier

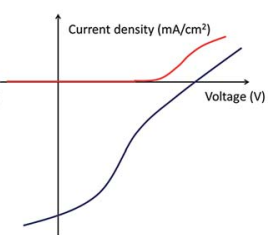

Fig. 1 Schematic illustration of energy level mismatch between the ntype metal oxides $\left(\mathrm{MeO}_{x}\right)$ and the acceptor of the active layer (PCBM) and corresponding $j-V$ curves in the organic solar cells. The red solid line indicates dark $j-V$ curves and the black solid line indicates illumination $j-V$ curves. Types of barrier: (a) injection barrier; (b) extraction barrier; (c) extraction and injection barriers.

combination with bias dependent photocurrent $\left(3^{\text {rd }} / 4^{\text {th }}\right.$ quadrant)..$^{25}$

Defects or dangling bonds on the surface of the $\mathrm{MeO}_{\mathrm{x}}$ nanocrystals promote the formation of defect states within the $\mathrm{MeO}_{\mathrm{x}}$ bandgap, which may act as charge trap sites or even recombination centers. ${ }^{14,26-29}$

In summary, the prevision discussion outlines the relevance of a careful interface design. The interface design is essential to control interface barriers for charge harvesting, decrease the surface recombination, decrease the serial resistance as well as to enhance the selectivity of the contact. Various methods were reported to manipulate the organic semiconductor $/ \mathrm{MeO}_{\mathrm{x}}$ interface. Surface passivation by a functional interfacial dipole layer or by solvent treatment (e.g. ethanolamine, methanol and ethanol) was reported to improve the contact properties. ${ }^{19,30,31}$ The most popular interfacial dipole layers reported were self-assembled monolayers (SAMs), ${ }^{32,33}$ conjugated polyelectrolytes $(\mathrm{CPEs})^{21,34-36}$ or polyelectrolyte layers (PEs), ${ }^{37}$ which all enhanced the power efficiency of OSCs by reducing the work function difference between $\mathrm{MeO}_{\mathrm{x}}$ and PCBM and further by reducing defect or trap-assisted recombination at the interface.

In this study, a solution-processed barium hydroxide $\left(\mathrm{Ba}(\mathrm{OH})_{2}\right)$ layer is inserted between an n-type metal oxide (AZO) layer and the active layer (pDPP5T-2:PC ${ }_{61} \mathrm{BM}$ ) to explore the contact formation effects on the device performance. A remarkable enhancement of the device efficiency is found upon inserting a $\mathrm{Ba}(\mathrm{OH})_{2}$ layer, dominantly explained by the reduction of the energetic barrier at the $\mathrm{AZO} / \mathrm{PC}_{61} \mathrm{BM}$ interface. Upon inserting a $\mathrm{Ba}(\mathrm{OH})_{2}$ layer, the PCE increases from $3.33 \%$ to $6.01 \%$, resembling an improvement of app. $80 \%$. The surface dipole between organic semiconductors and n-type metal oxides opens up alternative methods for the interface design of organic solar cells.

\section{Results and discussion}

The inverted device architecture and the molecular structures of the low bandgap diketopyrrolopyrrole-quinquethiophene alternating copolymer pDPP5T-2 and phenyl-C61-butyric acid methyl ester $\left(\mathrm{PC}_{61} \mathrm{BM}\right)$ are shown in Fig. 2a. The energy level diagram of the devices is shown in Fig. 2b. The current densityvoltage $(j-V)$ characteristics of typical inverted organic solar cells based on different electron transport layers without and with $\mathrm{Ba}(\mathrm{OH})_{2}$ are shown in Fig. 3, and a summary of the device performance is tabulated in Table 1. The control device with bare $\mathrm{AZO}$ as an electron transport layer exhibits an open circuit voltage $\left(V_{\mathrm{OC}}\right)$ of $0.50 \mathrm{~V}$, a short circuit current density $\left(\mathrm{JCC}_{\mathrm{SC}}\right)$ of $12.31 \mathrm{~mA} \mathrm{~cm}{ }^{-2}$, a fill factor (FF) of $53.90 \%$ and a power conversion efficiency (PCE) of $3.33 \%$. The series resistance $\left(R_{\mathrm{S}}\right)$ is $1.05 \Omega \mathrm{cm}^{2}$ and the shunt resistance $\left(R_{\text {Shunt }}\right)$ is $11.58 \mathrm{~K} \Omega \mathrm{cm}^{2}$. When a $\mathrm{Ba}(\mathrm{OH})_{2}$ layer is inserted between $\mathrm{AZO}$ and the active layer, $J_{\mathrm{SC}}$ increased from $12.31 \mathrm{~mA} \mathrm{~cm}{ }^{-2}$ to $15.79 \mathrm{~mA} \mathrm{~cm}{ }^{-2}, V_{\mathrm{OC}}$ from $0.50 \mathrm{~V}$ to $0.55 \mathrm{~V}$ and $\mathrm{FF}$ from $53.90 \%$ to $69.18 \%$. The PCE increases significantly up to $6.01 \%$, and the improvement is

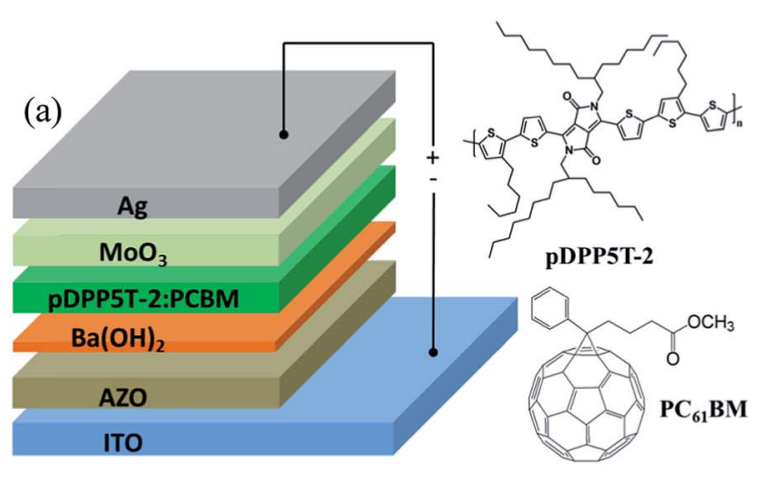

(b)

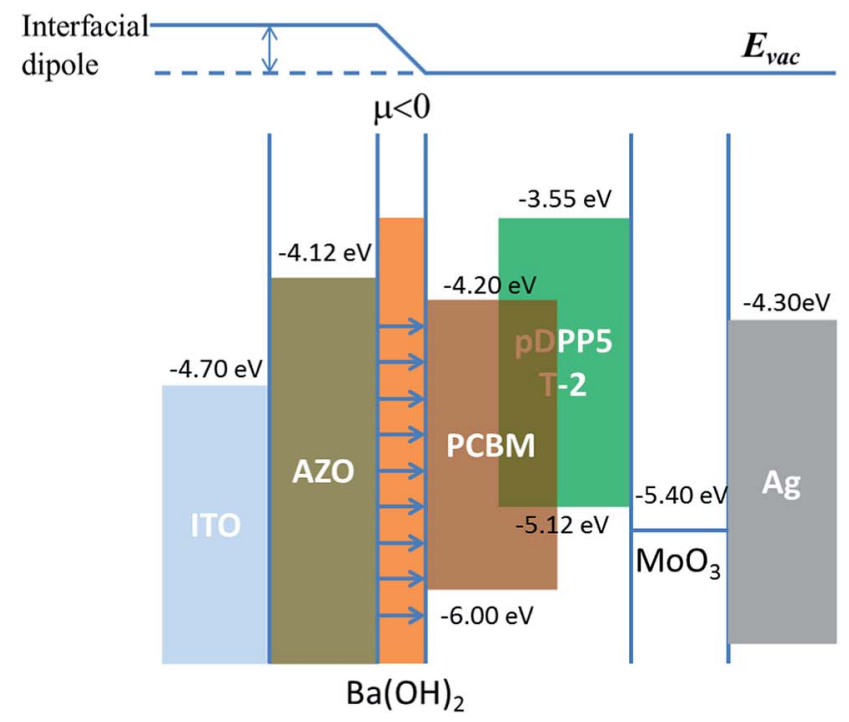

Fig. 2 (a) Schematic of the inverted organic solar cell structures and chemical structures of pDPP5T-2 and $\mathrm{PC}_{61} \mathrm{BM}$. (b) Energy level diagram of the organic solar cells investigated in this work. 

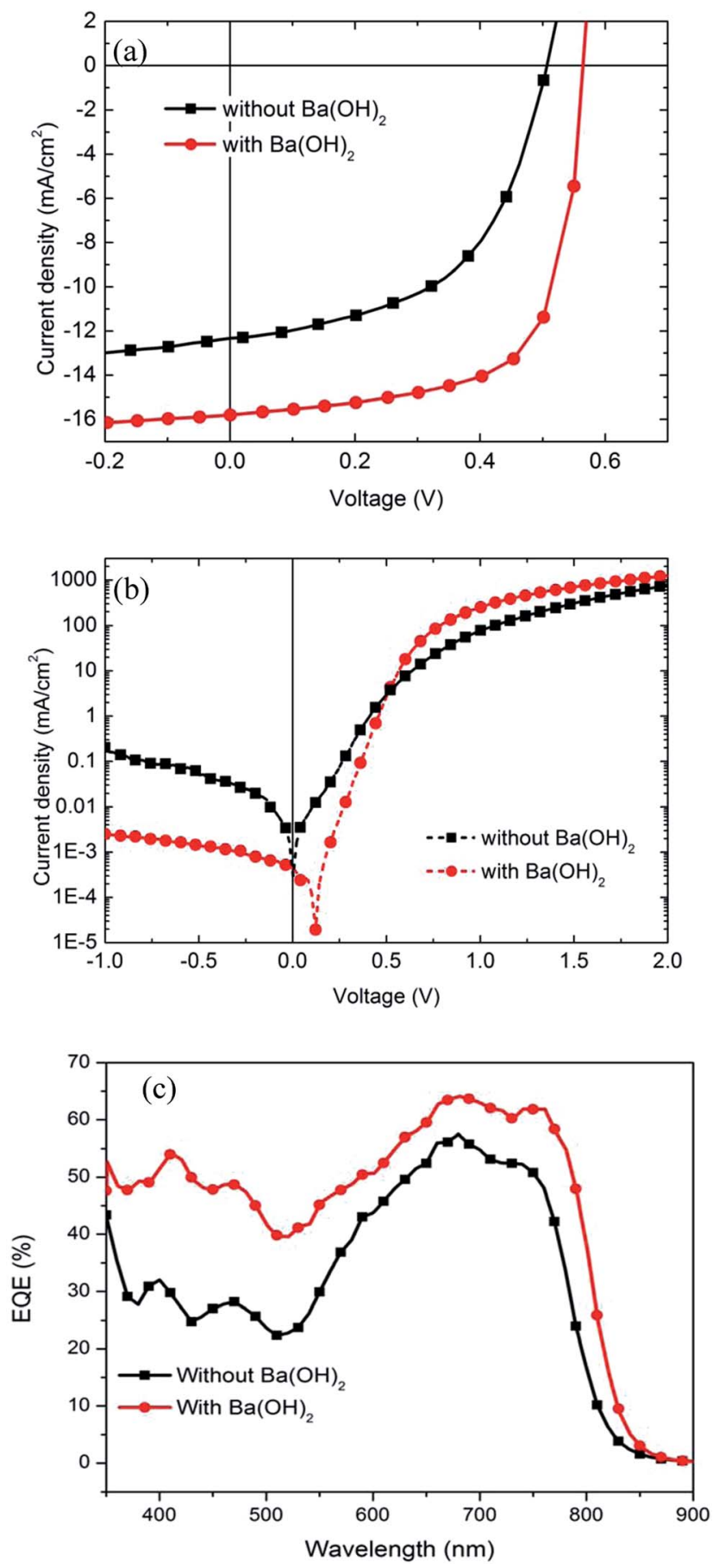

Fig. 3 (a) $j-V$ characteristics of inverted organic solar cells without and with the $\mathrm{Ba}(\mathrm{OH})_{2}$ layer. (b) Corresponding logarithmic plot of dark $j-\mathrm{V}$ characteristics. (c) EQE spectra of inverted organic solar cells without and with the $\mathrm{Ba}(\mathrm{OH})_{2}$ layer.

mainly due to a higher $J_{\mathrm{SC}}$ and an increased FF. Fig. 3a shows that the photocurrent density of the device with $\mathrm{Ba}(\mathrm{OH})_{2}$ is higher than that of the one without $\mathrm{Ba}(\mathrm{OH})_{2}$ under illumination. This is in agreement with the assumption that the $\mathrm{Ba}(\mathrm{OH})_{2}$ layer managed to reduce the extraction barrier. In parallel, Fig. 3b shows that the injected current density in the dark $(0.7-2.0 \mathrm{~V})$ is higher than that of the device without $\mathrm{Ba}(\mathrm{OH})_{2}$ and the series resistance decreased from $1.05 \Omega \mathrm{cm}^{2}$ to $0.88 \Omega \mathrm{cm}^{2}$. This is in agreement with a reduced injection barrier. To optimize the thickness of the $\mathrm{Ba}(\mathrm{OH})_{2}$ layer, the $\mathrm{Ba}(\mathrm{OH})_{2}$ solution with different concentrations was doctor bladed on top of the AZO layer (see Fig. S1, ESI $\dagger$ ). The best device performance with respect to all key parameters $\mathrm{FF}, J_{\mathrm{SC}}$, and $V_{\mathrm{OC}}$ is achieved for the device with an approximately $10 \mathrm{~nm}$ thick $\mathrm{Ba}(\mathrm{OH})_{2}$ layer. The distribution of photovoltaic parameters of over 6 solar cells is depicted in Fig. S2.†

Moreover, we investigated various alternative combinations of electron transport layers. Among them, various sol-gel processed AZO layers as well as $\mathrm{TiO}_{2}$ layers were studied. Most noteworthy, we found that pDPPT5-2 is very sensitive to the nature of $\mathrm{MeO}_{\mathrm{x}}$, and performance as well as reproducibility greatly varied as among the various $\mathrm{MeO}_{\mathrm{x}}$ layers. The insertion of the $\mathrm{BaOH}_{2}$ layer fixed both these problems - on the one hand, performance could be further optimized and on the other hand, the $\mathrm{BaOH}_{2}$ layer gave reasonable good performance for various $\mathrm{MeO}_{\mathrm{x}}$ layers. The corresponding $j-V$ characteristics of devices with $\mathrm{TiO}_{2}$ as electron transport layers are presented in Fig. S3. $\dagger$

The external quantum efficiency (EQE) spectra of both devices are shown in Fig. $3 c$. The $J_{\mathrm{SC}}$ values calculated from the $\mathrm{EQE}$ data are $11.78 \mathrm{~mA} \mathrm{~cm}^{-2}$ for the device without $\mathrm{Ba}(\mathrm{OH})_{2}$ and $15.19 \mathrm{~mA} \mathrm{~cm}^{-2}$ for the device with $\mathrm{Ba}(\mathrm{OH})_{2}$, both being in good agreement with the experimental $J_{\mathrm{sc}}$ values. The EQE spectrum in Fig. 3c points out that $\mathrm{Ba}(\mathrm{OH})_{2}$ dominantly improves the response from a short wavelength regime $(350 \mathrm{~nm}-550 \mathrm{~nm})$, i.e., where $\mathrm{PC}_{61} \mathrm{BM}$ absorbs. Here, the quantum efficiency is nearly doubled from $28 \%$ to $50 \%$, while the $\mathrm{EQE}$ in the long wavelength regime $(550 \mathrm{~nm}-850 \mathrm{~nm})$ increases from app. 50-60\%. The higher EQE values of the device with a $\mathrm{Ba}(\mathrm{OH})_{2}$ layer in the $\mathrm{PC}_{61} \mathrm{BM}$ absorption region demonstrate that $\mathrm{AZO} / \mathrm{Ba}(\mathrm{OH})_{2}$ more efficiently extracts electrons from $\mathrm{PC}_{61} \mathrm{BM}$, thus successfully reducing recombination at or around the interface between the AZO and the active layer. Several factors may play a role there - a reduction of the extraction barrier does suppress bulk recombination due to a lower local charge carrier density. Further, and since $\mathrm{Ba}(\mathrm{OH})_{2}$ has a deep $\mathrm{HOMO},{ }^{38}$ a confinement of holes in the active layer would reduce surface recombination.

To investigate the effect of the $\mathrm{Ba}(\mathrm{OH})_{2}$ layer on the diode properties of the devices, we analyzed the dark current characteristics as shown in Fig. 3b, using the equivalent circuit model. ${ }^{39,40}$ In this model, the $j-V$ characteristics can be derived by the following eqn (1):

$J=J_{0}\left\{\exp \left[\frac{q\left(V-J A R_{\mathrm{s}}\right)}{n k T}\right]-1\right\}+\left(V-J A R_{\mathrm{s}}\right) / A R_{\mathrm{sh}}-J_{\mathrm{ph}}(V)$

where $J_{0}, q, n, R_{\mathrm{s}}, R_{\mathrm{sh}}, k, T$, and $A$ are the reverse saturation current density, elementary charge, ideality factor, series resistance, shunt resistance, Boltzmann constant, absolute temperature, and the active area of the device, respectively. By measuring the dark current density while sweeping the bias voltage, the diode characteristics including saturation current density $\left(J_{0}\right)$, diode ideality factor $(n)$, series resistance, and shunt resistance can be evaluated. When the linear fitting is 
Table 1 Key values of the $j-V$ characteristics of inverted organic solar cells without and with the $\mathrm{Ba}(\mathrm{OH})_{2}$ layer

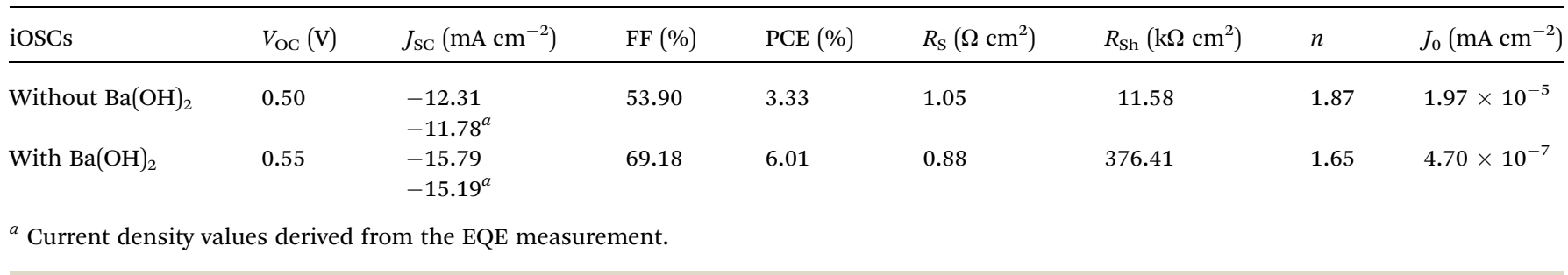

extrapolated versus $0 \mathrm{~V}, J_{0}$ can be calculated from the $y$-axis intercept while the diode ideality factor is determined by the slope of the line, ${ }^{\mathbf{4 0}}$ as shown in Fig. S5.† The parameters related to the diode properties $\left(J_{0}\right.$ and $\left.n\right)$ are summarized in Table 1. The lower $J_{0}$ value $\left(4.70 \times 10^{-7} \mathrm{~mA} \mathrm{~cm}^{-2}\right)$ of the device with $\mathrm{Ba}(\mathrm{OH})_{2}$ stands for a significantly reduced junction leakage current density. Typically, OPV bulk heterojunction (BHJ) cells have more than one diode, with the $\mathrm{BHJ}$ as the most prominent one formed between the polymer and the fullerene, and with one or two planar heterojunction diodes at the semiconductor/ charge extraction layer. A leakage current is associated with each of them. The significant reduction of the leakage current due to insertion of a $\mathrm{Ba}(\mathrm{OH})_{2}$ layer strongly suggests this interface as the problematic one. Charge extraction layers with insufficient selectivity lead to various phenomena, among them are the so-called photoshunt, photoconductivity or enhanced leakage currents. ${ }^{\mathbf{4 1 4 2}}$ The dominant factor to suppress the reverse saturation current is then ascribed to the formation of a more selective contact between AZO and the semiconductor. Here, this is in agreement with an increase of the injection barrier for minority carriers, i.e. holes from ITO into the HOMO level of P3HT. In other words, the insertion of a $\mathrm{Ba}(\mathrm{OH})_{2}$ layer facilitates electron injection while hampering in parallel hole injection.

There are two processes dominating the ideality factor $(n)$ in OSCs, both related to recombination phenomena at different time scales. It is known that excitons generated under illumination in the active layer must diffuse into the donor-acceptor (D-A) interface (sub-nanosecond regime). After dissociation, the individual carriers are transported in the respective donor and acceptor phases to the electrodes (nanosecond-microsecond regime). ${ }^{\mathbf{1 , 2 , 6 , 2 0}}$ The first process is exciton diffusion, where geminate bulk recombination is dominant; the second process is charge transport and charge accumulation at the respective organic/electrode interfaces, with the $1^{\text {st }}$ order or the $2^{\text {nd }}$ order recombination (trap induced or even space charge induced) being dominant. ${ }^{\mathbf{2 0 , 3 9 , 4 3}}$ Both processes do induce the loss of charge carriers and enlarge $n$, thus reducing FF. Devices with $n \gg 1$ typically suffer from high electron-hole recombination, which is of $2^{\text {nd }}$ or higher order. ${ }^{39}$ For devices without $\mathrm{Ba}(\mathrm{OH})_{2}$, an ideality factor of $n=1.87$ is typically indicative for higher order bulk recombination or for enhanced recombination at an interface due to charge accumulation. Surface charge accumulation functions as a major FF limitation, either via surface recombination or via enhanced bulk recombination due to delayed extraction. ${ }^{\mathbf{4}}$ The significant reduction of the diode ideality factor upon insertion of a $\mathrm{Ba}(\mathrm{OH})_{2}$ layer strongly suggests that charge accumulation at an interface in combination with an extraction barrier is a dominant loss mechanism in the devices without $\mathrm{Ba}(\mathrm{OH})_{2}$.

In order to further investigate the effect of $\mathrm{Ba}(\mathrm{OH})_{2}$, we performed capacitance versus voltage $(C-V)$ measurements for solar cells without and with $\mathrm{Ba}(\mathrm{OH})_{2}$, as shown in Fig. 4. Two important parameters can be read directly from $C-V$ plots. The built-in voltage $\left(V_{\mathrm{bi}}\right)$ is defined by the intersection of the $1 / C^{2}$ curve and the horizontal bias axis. On the other hand, the upper-limit of the dopand (carrier) density $(N)$ is determined from the slope of the Mott-Schottky plot using $N=-2\left(\mathrm{~d} C(x)^{2} / \mathrm{d} V\right)^{-1} / q \varepsilon_{0} \varepsilon_{\mathrm{r}} A^{2},{ }^{30,44}$ where $q$ accounts for the elementary charge, $\varepsilon_{0}$ is the dielectric constant of vacuum, $\varepsilon_{\mathrm{r}}$ is the relative dielectric constant of the semiconductor (assuming an $\varepsilon_{\mathrm{r}}$ of 3.5), ${ }^{45}$ and $A$ corresponds to the device active area. ${ }^{30}$ This analysis provides an appropriate comparison of the differences in $V_{\text {bi }}$ and $N$ between devices without and with $\mathrm{Ba}(\mathrm{OH})_{2}$. We find that $V_{\mathrm{bi}}$ is slightly increased in the devices with an inserted $\mathrm{Ba}(\mathrm{OH})_{2}$ layer, resulting in an enhanced electrical field supporting charge carrier extraction. Devices without $\mathrm{Ba}(\mathrm{OH})_{2}$ showed a $V_{\text {bi }}$ of approximately $0.51 \pm 0.01 \mathrm{~V}$ and a maximum dopand density of around $4.97 \times 10^{18} \mathrm{~cm}^{-3}$. Compared to the devices with a $\mathrm{Ba}(\mathrm{OH})_{2}$ layer, $V_{\mathrm{bi}}$ increased to $0.55 \pm 0.01 \mathrm{~V}$ and the maximum value of $N$ increases as well to approximately

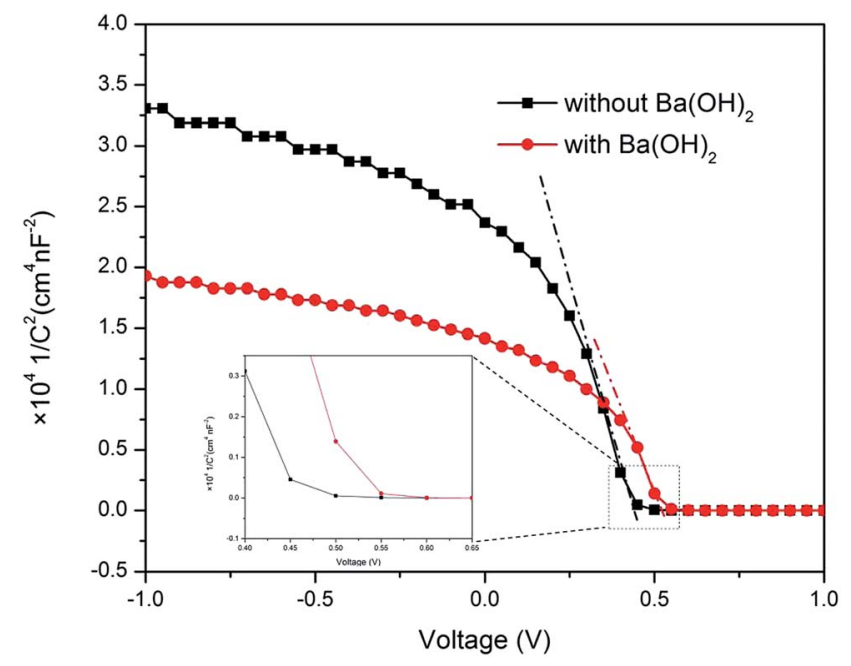

Fig. 4 Mott-Schottky capacitance plots for the data of voltage of the device without and with the $\mathrm{Ba}(\mathrm{OH})_{2}$ layer. Inset: the intercept with the voltage axis yields the built-in voltage. 
$6.55 \times 10^{18} \mathrm{~cm}^{-3}$. The increased dopand density $(N)$ suggests an increase in the surface charge density, either by an absolute higher number or by a reduced thickness of the charged regime. Based on previous reports on other alkali-based interfaces, ${ }^{46}$ this increase in the surface charge density can be attributed to interactions of $\mathrm{Ba}^{2+}$ ions with the surface of the active layer, giving rise to interfacial ionic charge doping. The arrangement of $\mathrm{Ba}^{2+}$ ions is suggested to dominantly promote a reduction of the electron extraction barrier, enhancing the extraction of carriers from $\mathrm{PC}_{61} \mathrm{BM}$ to $\mathrm{AZO} .{ }^{47}$ The nature of the interaction between $\mathrm{PC}_{61} \mathrm{BM}$ and $\mathrm{Ba}^{2+}$ is not understood in detail, but will be determined by chemical interaction aspects as well as microstructure related aspects like vertical phase segregation. ${ }^{48}$ It is noteworthy to mention that a reduction of the barrier is further expected to enhance electron injection from AZO into $\mathrm{PC}_{61} \mathrm{BM}$ as well. The impact of $\mathrm{Ba}(\mathrm{OH})_{2}$ on the energy band diagram at the $\mathrm{AZO}-\mathrm{PC}_{61} \mathrm{BM}$ interface is summarized in Fig. 5. Depending on the nature of the interaction between $\mathrm{Ba}^{2+}$ and $\mathrm{AZO}$, an interface dipole is expected to form. We suspect that the formation of a low work function $\mathrm{Zn}-\mathrm{O}-\mathrm{Ba}$ complex facilitates electron extraction in polymer solar cells. A thin layer of $\mathrm{O}-\mathrm{Ba}$ is formed at the AZO or the $\mathrm{TiO}_{2}$ surface with $\mathrm{Ba}$ ions toward the active layer. Yang Yang et al. reported that there is a similar possibility for the formation of $\mathrm{O}-\mathrm{M}$ structures. ${ }^{49} \mathrm{O}-\mathrm{Ba}$ replaces the hydroxyl group on the $\mathrm{AZO}$ or the $\mathrm{TiO}_{2}$ surface by surface chemical reaction: $-\mathrm{OH}+\mathrm{Ba}^{+} \rightarrow-\mathrm{O}-\mathrm{Ba}+\mathrm{H}^{+}$, similar to chemisorption of Cl-terminated molecules onto ITO. The interface dipoles with a negative charge toward AZO and the corresponding positive charge toward the active layer result in the lowering of the vacuum level of AZO.

In addition, a $\mathrm{Ba}(\mathrm{OH})_{2}$ layer enhances electron injection and transport at the cathode by lowering the work function of AZO and further reduces the inherent incompatibility between the AZO layer and the active layer. The energy band diagrams for AZO/active layer junctions with and without $\mathrm{Ba}(\mathrm{OH})_{2}$ are illustrated in Fig. 5. For higher device efficiency, the conduction band of AZO should match well with the LUMO of $\mathrm{PC}_{61} \mathrm{BM}$. After the $\mathrm{Ba}(\mathrm{OH})_{2}$ layer deposition, the work function of AZO decreases from $4.40 \mathrm{eV}$ to $4.12 \mathrm{eV}$, which is attributed to the "push-back" or the "cushion" effect, ${ }^{24,50}$ according to the results of Kelvin probe microscopy (KPM) measurements. The

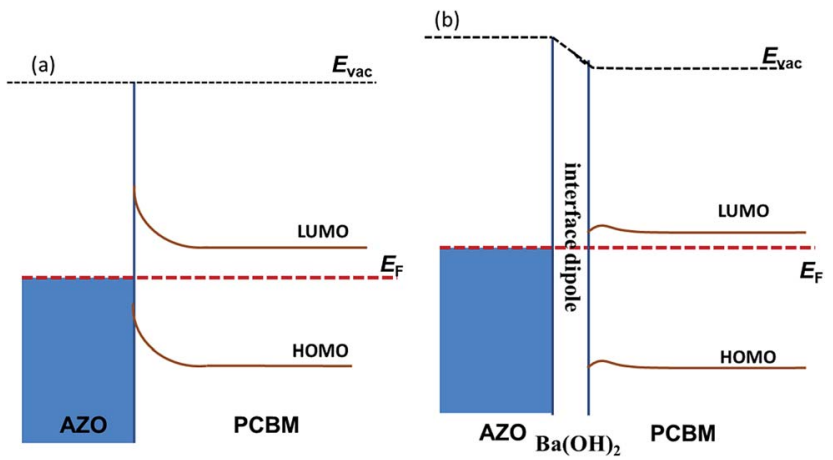

Fig. 5 Schematic energy diagrams for band conditions at the AZO/ $\mathrm{PC}_{61} \mathrm{BM}$ junctions without (a) and with (b) $\mathrm{Ba}(\mathrm{OH})_{2}$ on the $\mathrm{AZO}$ layer. decreased work function of AZO facilitates electron extraction and transport by reducing the energy barrier between AZO and the active layer. Moreover, this directly results in an increased $V_{\mathrm{bi}}$ and exerts a strong electrical field at the active layer/cathode interface that may strongly influence charge transport and extraction. $^{51}$

An ultrathin $\mathrm{Ba}(\mathrm{OH})_{2}$ layer cannot form a continuous layer, which is confirmed by the atomic force microscope (AFM) image shown in Fig. $\mathrm{S} 4 . \dagger$ The $\mathrm{Ba}(\mathrm{OH})_{2}$ layer on $\mathrm{AZO}$ still displays a mountain-chain like morphology, and it is the similar to that of AZO. The AZO film has a root mean square (RMS) roughness value around $8.26 \mathrm{~nm}$, as shown in Fig. S4a. $\dagger$ An ultrathin $\mathrm{Ba}(\mathrm{OH})_{2}$ layer deposited on AZO is only slightly smoother than bare AZO, and the RMS roughness decreases to $6.07 \mathrm{~nm}$. The RMS roughness of a pDPP5T-2: $\mathrm{PC}_{61} \mathrm{BM}$ film on the AZO layer without and with $\mathrm{Ba}(\mathrm{OH})_{2}$ insertion is 2.25 and $2.06 \mathrm{~nm}$, respectively.

To investigate the influence of $\mathrm{Ba}(\mathrm{OH})_{2}$ layers on the bulk of the active layer, we examined the carrier mobilities of pDPP5T2: $\mathrm{PC}_{61} \mathrm{BM}$ by using electron-only diodes and the space-charge limited current (SCLC) model. ${ }^{51}$ Electron-only devices are fabricated with a device architecture of ITO/AZO/without or with $\mathrm{Ba}(\mathrm{OH})_{2} /$ pDPP5T-2:PC ${ }_{61} \mathrm{BM} / \mathrm{Ca} / \mathrm{Ag}$. The electron mobility of the electron-only devices is fit using the Mott-Gurney law, and the box charts are obtained from $j-V$ fitting on 12 electron-only devices, as shown in Fig. S6. $\dagger$ In a pristine device without $\mathrm{Ba}(\mathrm{OH})_{2}$, the average electron mobility is calculated to be $3.42 \times$ $10^{-3} \mathrm{~cm}^{2} \mathrm{~V}^{-1} \mathrm{~s}^{-1}$. Interestingly, the device with $\mathrm{Ba}(\mathrm{OH})_{2}$ shows the similar average electron mobility of $4.70 \times 10^{-3} \mathrm{~cm}^{2} \mathrm{~V}^{-1} \mathrm{~s}^{-1}$. The electron current density of the device without $\mathrm{Ba}(\mathrm{OH})_{2}$ is slightly lower than that of the device with $\mathrm{Ba}(\mathrm{OH})_{2}$, which suggests that the presence of $\mathrm{Ba}(\mathrm{OH})_{2}$ actually has no effect on the electron mobility of the bulk active layer in OSCs. Nevertheless, slight changes in the microstructure very close to the interface of the active layer and the modified AZO layer cannot be completely excluded with these results. In other words, the improvement in device performance after the insertion of $\mathrm{Ba}(\mathrm{OH})_{2}$ originates mainly from an interfacial effect between the active layer and $\mathrm{Ba}(\mathrm{OH})_{2}{ }^{52}$

In addition, we have investigated the effect of $\mathrm{Ba}(\mathrm{OH})_{2}$ for P3HT: $\mathrm{PC}_{61} \mathrm{BM}$ blends. The $\mathrm{Ba}(\mathrm{OH})_{2}$ layer has a similar effect in $\mathrm{P} 3 \mathrm{HT}: \mathrm{PC}_{61} \mathrm{BM}$ blends. The main influence of $\mathrm{Ba}(\mathrm{OH})_{2}$ modification is observed on the $J_{\mathrm{SC}}$ and FF enhancement. Although $V_{\text {OC }}$ has not shown observable change, this difference can be attributed to the different processing, post treatment and morphology of P3HT-based devices compared to the DPP-based devices. The corresponding $j-V$ characteristics are presented in Fig. S7.†

\section{Conclusions}

In conclusion, high efficiency iOSCs (ITO/AZO/Ba(OH) $/$ pDPP5T-2:PC ${ }_{61} \mathrm{BM} / \mathrm{MoOX} / \mathrm{Ag}$ ) with a PCE of $6.01 \%$ are achieved by inserting a $\mathrm{Ba}(\mathrm{OH})_{2}$ layer, which tunes the barrier between the conduction band of $\mathrm{AZO}$ and the LUMO of $\mathrm{PC}_{61} \mathrm{BM}$ in the active layer. Compared to the control device (without the $\mathrm{Ba}(\mathrm{OH})_{2}$ layer), the iOSCs with the $\mathrm{Ba}(\mathrm{OH})_{2}$ layer show an 
enhanced $V_{\mathrm{OC}}$ of $10 \%, J_{\mathrm{SC}}$ of $28 \%$, FF of $28 \%$, and PCE of $80 \%$. The effects of a $\mathrm{Ba}(\mathrm{OH})_{2}$ layer on the improvement of device performance originate on one hand from the decreased energy barrier for electron extraction and injection and consequently reduced interface charge recombination and on the other hand from the increased built-in potential from a corresponding increase of surface charge density. Furthermore, compared to SAMs, CPEs and PEs as interfacial dipole layer materials, the $\mathrm{Ba}(\mathrm{OH})_{2}$ layer is cost-effective and can simply be fabricated in ambient atmosphere, thereby easing the processing requirements. This strategy of inserting a $\mathrm{Ba}(\mathrm{OH})_{2}$ layer suggests a promising and practical route to improve the efficiency of OSCs at an industrial fabrication level.

\section{Experimental section}

\section{Materials}

pDPP5T-2 (batch: GKS1-001) was provided by BASF. PC ${ }_{61} \mathrm{BM}$ $(99 \%)$ was purchased from Solenne BV. $\mathrm{Ba}(\mathrm{OH})_{2}$ was purchased from Sigma-Aldrich. All materials were used as received.

\section{Synthesis of Al doped zinc oxide}

$\mathrm{Zn}(\mathrm{OAc})_{2} \cdot 2 \mathrm{H}_{2} \mathrm{O}(20 \mathrm{~g}), \mathrm{Al}(\mathrm{OH})(\mathrm{OAc})_{2}(0.3 \mathrm{~g})$ and Zonyl FSO-100 $(0.6 \mathrm{~g})$ were mixed in demineralized water $(200 \mathrm{~mL})$. The mixture was stirred for $2 \mathrm{~h}$ and filtered through a 0.45 micrometer filter to remove the insoluble material. The functionality of AZO in iOSCs was fully investigated previously. ${ }^{12}$

\section{Device processing}

All the devices were fabricated using doctor-blading under ambient conditions with the structures shown in Fig. 1. Prestructured ITO coated glass substrates were subsequently cleaned in acetone and isopropyl alcohol for $10 \mathrm{~min}$ each. After drying, the substrates were coated with the AZO solution via doctor blading. Conversion of the precursor to AZO via hydrolysis was achieved by heating the samples to $140{ }^{\circ} \mathrm{C}$ for $5 \mathrm{~min}$. The thickness of AZO films is approximately $40 \mathrm{~nm}$. The AZO precursor was synthesized as optimized and reported earlier based on zinc acetate and aluminum nitrate in ethanol. Subsequently, $\mathrm{Ba}(\mathrm{OH})_{2}$ was dissolved in 2-methoxyethanol ( $7 \mathrm{mg} \mathrm{ml}^{-1}$ ) and doctor bladed on top of the AZO layer with a thickness of $\approx 10 \mathrm{~nm}$ and then dried at $100{ }^{\circ} \mathrm{C}$ for $10 \mathrm{~min}$. Then, a $120 \mathrm{~nm}$ thick active layer based on pDPP5T-2:PC ${ }_{61} \mathrm{BM}(1: 2$, dissolved in a mixed solvent of $90 \%$ chloroform and $10 \%$ $o$-dichlorobenzene at a concentration of $24 \mathrm{mg} \mathrm{mL}^{-1}$ in total) was deposited on top of the $\mathrm{Ba}(\mathrm{OH})_{2}$ layer. Finally $10 \mathrm{~nm} \mathrm{MoO}_{3}$ and $100 \mathrm{~nm}$ Ag were deposited sequentially under $6 \times 10^{-6}$ Torr by thermal evaporation through a shadow mask to form an active area of $10.4 \mathrm{~mm}^{2}$.

\section{Characterization methods}

The current-voltage characteristics were measured using a source measurement unit from BoTest through a mask with an opening of $10.4 \mathrm{~mm}^{2}$. Illumination was provided by a solar simulator (Oriel Sol 1A, from Newport) with AM1.5G spectra at $100 \mathrm{~mW} \mathrm{~cm}^{-2}$. The EQE was detected with a Cary 500 Scan
UV-vis-NIR Spectrophotometer under monochromatic illumination, which was calibrated with a monocrystalline silicon diode. The morphology was investigated by AFM (Veeco Model D3100, tapping mode). The work function of various layers was measured by using a Kelvin probe (Kelvin Probe Technologies Inc., SKP5050) in air. The thicknesses of films were measured by using a profilometer (Tencor Alpha Step). The $C-V$ measurement was carried out with an Agilent HP 4192A Impedance Analyzer at a frequency of $50 \mathrm{~Hz}$.

\section{Acknowledgements}

The authors gratefully acknowledge the support of the Cluster of Excellence "Engineering of Advanced Materials (EAM)", Energy Campus Nuremberg (EnCN, Solarfactory), the "Synthetic Carbon Allotropes" (SFB 953) project and the Erlangen Graduate School in Advanced Optical Technologies (SAOT) at the University of Erlangen-Nuremberg, which is funded by the German Research Foundation (DFG) within the framework of its "Excellence Initiative". N. Li thanks the "roll to roll production of organic tandem cells" project (RotRot, Grant no. 288565) for financial support. This work was partially funded by the China Scholarship Council (CSC). Tobias Stubhan was funded by a German Research Foundation project grant (DFG; BR 4031/1-2).

\section{References}

1 C. J. Brabec, N. S. Sariciftci and J. C. Hummelen, Adv. Funct. Mater., 2001, 11, 15-26.

2 C. J. Brabec, S. Gowrisanker, J. J. M. Halls, D. Laird, S. J. Jia and S. P. Williams, Adv. Mater., 2010, 22, 3839-3856.

3 C. J. Brabec, Sol. Energy Mater. Sol. Cells, 2004, 83, 273-292.

4 G. Dennler, M. C. Scharber and C. J. Brabec, Adv. Mater., 2009, 21, 1323-1338.

5 M. A. Green, K. Emery, Y. Hishikawa, W. Warta and E. D. Dunlop, Prog. Photovoltaics, 2013, 21, 827-837.

6 H. Ma, H. L. Yip, F. Huang and A. K. Y. Jen, Adv. Funct. Mater., 2010, 20, 1371-1388.

7 C. Waldauf, M. Morana, P. Denk, P. Schilinsky, K. Coakley, S. A. Choulis and C. J. Brabec, Appl. Phys. Lett., 2006, 89, 233517.

8 H. Zhang, M. F. Xu, R. L. Cui, X. H. Guo, S. Y. Yang, L. S. Liao, Q. J. Jia, Y. Chen, J. Q. Dong and B. Y. Sun, Nanotechnology, 2013, 24, 355401.

9 Y. M. Sun, J. H. Seo, C. J. Takacs, J. Seifter and A. J. Heeger, Adv. Mater., 2011, 23, 1679-1683.

10 M. S. White, D. C. Olson, S. E. Shaheen, N. Kopidakis and D. S. Ginley, Appl. Phys. Lett., 2006, 89, 143517.

11 T. Stubhan, H. Oh, L. Pinna, J. Krantz, I. Litzov and C. J. Brabec, Org. Electron., 2011, 12, 1539-1543.

12 T. Stubhan, I. Litzov, N. Li, M. Salinas, M. Steidl, G. Sauer, K. Forberich, G. J. Matt, M. Halik and C. J. Brabec, J. Mater. Chem. A, 2013, 1, 6004-6009.

13 M. Jorgensen, K. Norrman and F. C. Krebs, Sol. Energy Mater. Sol. Cells, 2008, 92, 686-714. 
14 S. M. Sze and K. K. Ng, Physics of semiconductor devices, Wiley-Interscience, Hoboken, N.J., 3rd edn, 2007.

15 W. Tress, K. Leo and M. Riede, Adv. Funct. Mater., 2011, 21, 2140-2149.

16 K. Walzer, B. Maennig, M. Pfeiffer and K. Leo, Chem. Rev., 2007, 107, 1233-1271.

17 L. Schmidt-Mende and J. L. MacManus-Driscoll, Mater. Today, 2007, 10, 40-48.

18 M. Graetzel, R. A. J. Janssen, D. B. Mitzi and E. H. Sargent, Nature, 2012, 488, 304-312.

19 B. R. Lee, E. D. Jung, Y. S. Nam, M. Jung, J. S. Park, S. Lee, H. Choi, S. J. Ko, N. R. Shin, Y. K. Kim, S. O. Kim, J. Y. Kim, H. J. Shin, S. Cho and M. H. Song, Adv. Mater., 2013, 3, 494-500.

20 E. L. Ratcliff, B. Zacher and N. R. Armstrong, J. Phys. Chem. Lett., 2011, 2, 1337-1350.

21 H. Choi, J. S. Park, E. Jeong, G. H. Kim, B. R. Lee, S. O. Kim, M. H. Song, H. Y. Woo and J. Y. Kim, Adv. Mater., 2011, 23, 2759-2763.

22 W. Tress, S. Corvers, K. Leo and M. Riede, Adv. Energy Mater., 2013, 3, 873-880.

23 W. Tress, A. Merten, M. Furno, M. Hein, K. Leo and M. Riede, Adv. Energy Mater., 2013, 3, 631-638.

24 S. Braun, W. R. Salaneck and M. Fahlman, Adv. Mater., 2009, 21, 1450-1472.

25 W. Tress and O. Inganas, Sol. Energy Mater. Sol. Cells, 2013, 117, 599-603.

26 C. Kittel, Introduction to solid state physics, Wiley, Hoboken, NJ, 8th edn, 2005.

27 E. H. Nicollian and J. R. Brews, MOS (metal oxide semiconductor) physics and technology, Wiley-Interscience, Hoboken, N.J., Wiley classics library edn, 2003.

28 S. Olibet, E. Vallat-Sauvain and C. Ballif, Phys. Rev. B: Condens. Matter Mater. Phys., 2007, 76, 035326.

29 X. B. Chen, L. Liu, P. Y. Yu and S. S. Mao, Science, 2011, 331, 746-750.

30 H. Q. Zhou, Y. Zhang, J. Seifter, S. D. Collins, C. Luo, G. C. Bazan, T. Q. Nguyen and A. J. Heeger, Adv. Mater., 2013, 25, 1646-1652.

31 X. F. Liu, W. Wen and G. C. Bazan, Adv. Mater., 2012, 24, 4505-4510.

32 T. Stubhan, M. Salinas, A. Ebel, F. C. Krebs, A. Hirsch, M. Halik and C. J. Brabec, Adv. Energy Mater., 2012, 2, 532535.

33 H. L. Yip, S. K. Hau, N. S. Baek, H. Ma and A. K. Y. Jen, Adv. Mater., 2008, 20, 2376-2382.
34 J. Min, H. Zhang, T. Stubhan, Y. N. Luponosov, M. Kraft, S. A. Ponomarenko, T. Ameri, U. Scherf and C. J. Brabec, J. Mater. Chem. A, 2013, 1, 11306-11311.

35 T. B. Yang, M. Wang, C. H. Duan, X. W. Hu, L. Huang, J. B. Peng, F. Huang and X. Gong, Energy Environ. Sci., 2012, 5, 8208-8214.

36 J. H. Seo, A. Gutacker, Y. M. Sun, H. B. Wu, F. Huang, Y. Cao, U. Scherf, A. J. Heeger and G. C. Bazan, J. Am. Chem. Soc., 2011, 133, 8416-8419.

37 A. K. K. Kyaw, D. H. Wang, V. Gupta, J. Zhang, S. Chand, G. C. Bazan and A. J. Heeger, Adv. Mater., 2013, 25, 23972402.

38 L. P. Lu, D. Kabra and R. H. Friend, Adv. Funct. Mater., 2012, 22, 4165-4171.

39 B. Y. Qi and J. Z. Wang, Phys. Chem. Chem. Phys., 2013, 15, 8972-8982.

40 J. H. Lee, S. Cho, A. Roy, H. T. Jung and A. J. Heeger, Appl. Phys. Lett., 2010, 96, 163303.

41 C. Waldauf, M. C. Scharber, P. Schilinsky, J. A. Hauch and C. J. Brabec, J. Appl. Phys., 2006, 99, 104503.

42 P. Schilinsky, C. Waldauf, J. Hauch and C. J. Brabec, J. Appl. Phys., 2004, 95, 2816-2819.

43 M. M. Mandoc, W. Veurman, L. J. A. Koster, B. de Boer and P. W. M. Blom, Adv. Funct. Mater., 2007, 17, 2167-2173.

44 B. B. Chen, X. F. Qiao, C. M. Liu, C. Zhao, H. C. Chen, K. H. Wei and B. Hu, Appl. Phys. Lett., 2013, 102, 193302.

45 P. W. M. Blom, V. D. Mihailetchi, L. J. A. Koster and D. E. Markov, Adv. Mater., 2007, 19, 1551-1566.

46 L. P. Lu, D. Kabra, K. Johnson and R. H. Friend, Adv. Funct. Mater., 2012, 22, 144-150.

47 H. B. Wang, P. Amsalem, G. Heimel, I. Salzmann, N. Koch and M. Oehzelt, Adv. Mater., 2014, 26, 925-930.

48 M. Campoy-Quiles, T. Ferenczi, T. Agostinelli, P. G. Etchegoin, Y. Kim, T. D. Anthopoulos, P. N. Stavrinou, D. D. C. Bradley and J. Nelson, Nat. Mater., 2008, 7, 158-164.

49 J. S. Huang, Z. Xu and Y. Yang, Adv. Funct. Mater., 2007, 17, 1966-1973.

50 G. Witte, S. Lukas, P. S. Bagus and C. Woll, Appl. Phys. Lett., 2005, 87, 263502.

51 Z. C. He, C. M. Zhong, X. Huang, W. Y. Wong, H. B. Wu, L. W. Chen, S. J. Su and Y. Cao, Adv. Mater., 2011, 23, 4636-4643.

52 H. Ishii, K. Sugiyama, E. Ito and K. Seki, Adv. Mater., 1999, 11, 972 . 